\title{
Pengaruh Citra Merek dan Kepuasan Konsumen Terhadap Loyalitas Merek Mie Instan Indomie pada Alfamart Cabang Putat
}

\author{
Novi Rukhviyanti ${ }^{1}$, Sepryhatin Dioputra ${ }^{2}$, Ujang Cepi Barlian ${ }^{3}$, \\ Muhammad Furqon ${ }^{4}$ \\ 1,2,3,4 Program Studi Manajemen \\ Sekolah Tinggi Ilmu Ekonomi STAN IM, Jl. Belitung No.7 Bandung
}

Email : novi.rukhviyanti@stmik-im.ac.id ${ }^{1}$, sepryhatindioputra@ rocketmail.com², ujangcepibarlian@yahoo.co.id ${ }^{3}$, muhfurqon2020@gmail.com ${ }^{4}$

\begin{abstract}
ABSTRAK
Penelitian ini bertujuan menganalisis pengaruh citra merek dan kepuasan konsumen terhadap loyalitas merek mie instan indomie pada Alfamart Cabang Putat. Penelitian ini menggunakan variabel independen yaitu citra merek dan kepuasan konsumen dengan satu variabel dependen yaitu loyalitas merek. Sampel diambil dengan teknik incidental sampling, dengan jumlah sebanyak 41 responden. Metode pengumpulan data yang terkait dengan masalah penelitian dilakukan metode kuesioner. Teknik analisa menggunakan analisa regresi linier berganda. Hasil penelitian menunjukkan bahwa secara simultan citra merek dan kepuasan konsumen berpengaruh secara positif dan signifikan terhadap loyalitas merek. Secara parsial bahwa citra merek berpengaruh secara positif dan signifikan terhadap loyalitas merek, dan kepuasan konsumen berpengaruh secara positif dan signifikan terhadap loyalitas merek.
\end{abstract}

Kata Kunci : Citra Merek, Kepuasan Konsumen dan Loyalitas Merek

\section{ABSTRACT}

This study aims to analyze the effect of brand image and consumer satisfaction to brand loyalty indomie instan noodles at Alfamart Putat Branch.This study uses independent variabel, namely purchasing decisions. Samples were taken by incidential sampling technique, with a total sample of 41 respondents. Data collection methods related to the research problem were carried out usning a questionnarie method. Analyze techniques using multiple linear regression analyze. The result showed that is simultaneously that brand image and customer satisfaction had a positive and significant effect on brand loyalty. In partial, that the brand image have positive and significant effect on brand loyalty, while that customer satisfaction had a positive and significant effect on brand loyalty.

Keyword: Brand Image, Customer Satisfaction and Brand Loyalty

\section{PENDAHULUAN}

Citra merek merupakan bagian dari merek yang dapat dikenali (Nandya Ayu Putri, Zainul Arifin, 2016) Citra merek mempunyai peranan yang sangat penting bagi suatu perusahaan untuk membedakan suatu produk atau jasa dengan perusahaan yang 
lain. Produk yang telah memiliki citra merek yang kuat akan sulit ditiru karena telah tertanam dalam benak konsumen. Lain halnya dengan produk yang bisa dengan mudah ditiru karena presepsi konsumen atas nilai suatu merek tertentu itu tidak akan mudah diciptakan. Citra merek (brand image) yang kuat akan membuat konsumen memiliki presepsi untuk mendapat nilai tambah dari suatu produk yang tak akan didapatkan dari produk-produk lain. Tanpa citra yang kuat dan positif, sangatlah sulit bagi perusahaan utnuk menarik pelanggan baru dan mempertahankan pelanggan yang sudah ada agar tetap loyal, meskipun banyak produk mie instan di pasaran, tetapi masyarakat lebih menyukai mie Instan Indomie. Karena citra merek Indomie yang telah terbentuk sejak lama di pasar itulah yang mempengaruhi konsumen untuk memilihnya.

Kosumen yang puas akan membeli produk yang dijual oleh perusahaan, sekaligus menjadi pemasar yang efektif melalui word of mouth yang bernada positif. Saat ini Indomie masih menjadi market leader dalam industri mie instan, karena memiliki kelebihan jika dibandingkan dengan produk lain yang sejenis. Loyalitas merek merupakan faktor utama dalam meningkatkan pangsa pasar perusahaan. Loyalitas merek dapat terbentuk apabila konsumen memiliki sikap positif suatu merek yang ditandai dengan komitmen terhadap merek tersebut dan berencana untuk melakukan pembelian ulang dimasa yang akan datang.

Objek yang diambil dari penelitian ini adalah produk mie instan yaitu Mie Indomie. Sebagai perusahaan yang mempelopori makanan instan yang cepat saji, PT. Indofood Sukses Makmur Tbk telah berhasil mengarahkan konsumen pasar agar mengkonsumsi mie instan salah satunya merek Indomie dan membuat mie dalam kemasan diterima dengan baik dan positif dipasar indonesia. PT. Indofood Sukses Makmur Tbk pernah menjadi penguasa mutlak pasar mie instan dengan produk adanya Indomie. Namun Indofood sempat terlena me-maintain pasarnya sehingga kesempatan ini dimanfaatkan oleh pendatang baru Mie Sedap dari Wingsfood yang menyebabkan Indofood sempat kehilangan pangsa pasarnya (www.swa.com).

Penelitian sebelumnya terhadap loyalitas merek yang dilakukan oleh (Bastian, 2014), yang menyatakan bahwa variabel citra merek berpengaruh positif dan signifikan terhadap loyalitas merek. Tetapi ada juga peneliti terdahulu yang menyatakan bahwa variabel citra merek berpengaruh negatif terhadap variabel loyalitas merek dilakukan oleh (DEWI, 2015). Sedangkan untuk penelitian mengenai loyalitas merek yang 
dilakukan oleh (Hanifa et al., 2019) menyatakan bahwa variabel kepuasan konsumen berpengaruh positif dan signifikan terhadap variabel loyalitas merek. Tetapi ada juga peneliti terdahulu yang menyatakan variabel kepuasan konsumen berpengaruh negatif terhadap loyalitas merek dilakukan oleh (Purnama, 2018).

Berdasarkan penjelasan yang sudah dipaparkan di atas dan dengan adanya inkonsistensi dari penelitian-penelitian terdahulu maka peneliti ingin melakukan penelitian mengenai (1). Bagaimana Citra merek, Kepuasan Konsumen dan Loyalitas merek Mie Instan Indomie pada Alfamart Cabang Putat ?, (2). Bagaimana pengaruh Citra Merek terhadap Loyalitas Merek Mie Instan Indomie pada Alfamart Cabang Putat ?, (3). Bagaimana pengaruh Kepuasan Konsumen terhadap Loyalitas Merek Mie Instan Indomie pada Alfamart Cabang Putat ?, (4). Bagaimana pengaruh Citra Merek dan Kepuasan Konsumen secara bersama-sama terhadap Loyalitas Merek Mie Instan Indomie pada Alfamart Cabang Putat?

\section{METODE PENELITIAN}

Metode penelitian pada dasarnya merupakan cara ilmiah untuk mendapatkan data dengan tujuan dan kegunaan tertentu (Suliyanto, 2017). Metode penelitian yang digunakan dalam penelitian ini adalah metode penelitian kuantitatif dan deskriptif. Dalam melakukan penelitian ini membutuhkan data-data yang berhubungan dengan penelitian yang akan dilakukan, kemudian data di kumpulkan, dianalisis, dan di proses selanjutnya diuji sesuai dengan metode yang digunakan agar dapat ditarik kesimpulan.

Teknik pengambilan sampel yang digunakan pada penelitian ini menggunakan rumus slovin. Dalam penelitian ini populasinya adalah masyarakat Putat yang datang ke Alfamart untuk membeli dan mengkonsumsi mie instan indomie. Dalam penelitian ini tidak mungkin kita meneliti seluruh anggota populasi, untuk itu dibutuhkan membentuk seubuah perwakilan populasi yang disebut sampel. Teknik pengumpulan data merupakan langkah yang strategis dalam penelitian, karena tujuan dari penelitian ini adalah mendapatkan data. Tanpa mengetahui pengumpulan data, maka peneliti tidak akan mendapatkan data yang memenuhi standar data yang ditetapkan. Adapun data yang diperoleh dengan teknik pengumpulan data di lakukan dengan teknik wawancara dan kuisioner. 
Dalam penelitian ini untuk melakukan uji validitas dibantu dengan Software IBM SPSS dan dalam penelitian ini, uji relibilitas yang akan digunakan adalah teknik Alpha Cronbrach dimana teknik atau rumus ini digunakan untuk menentukan apakah suatu instrumen penelitian reliabel atau tidak.

\section{HASIL DAN PEMBAHASAN}

Dalam penelitian ini penulis melakukan analisis data secara deskriptif maupun statistik. Dalam penelitian ini gambaran karakteristik biografis responden yang ingin diketahui adalah jenis kelamin dan usia. Populasi dalam penelitian ini adalah masyarakat Putat yang membeli dan mengkonsumsi Mie Indomie berjumlah 240 (dua ratus empat puluh orang), Sedangkan sampel yang digunakan adalah 41 (empat puluh satu orang).

Responden yang telah melakukan pengisian kuesioner kemudian akan diidentifikasikan berdasarkan jenis kelamin dan usia. Gambaran umum dari responden sebagai subjek penelitian satu persatu dapat diuraikan seperti bagan berikut :

Tabel 1. Profil Responden Berdasarkan Jenis Kelamin

\begin{tabular}{ccc}
\hline Jenis Kelamin & Jumlah Responden & Presentase (\%) \\
\hline Laki-laki & 10 & $24,0 \%$ \\
\hline Perempuan & 31 & $76,0 \%$ \\
\hline Total & 41 & 100,0 \\
\hline
\end{tabular}

Berdasarkan tabel 1 responden yang mendominasi adalah responden perempuan sebanyak 31 responden 76,0\%), sedangkan responden laki-laki sebanyak 10 responden $(24,0 \%)$.

Tabel 2. Profil Responden Berdasarkan Usia

\begin{tabular}{ccc}
\hline Usia & Jumlah Responden & Presentase (\%) \\
\hline $18-21$ Tahun & 8 & $20,0 \%$ \\
\hline $22-24$ Tahun & 12 & $29,0 \%$ \\
\hline $25-27$ Tahun & 21 & $51,0 \%$ \\
\hline TOTAL & 41 & $100,0 \%$ \\
\hline
\end{tabular}

Berdasarkan tabel 2 proposi responden berdasarkan tingkat usia dibagi kedalam 2 tingkatan, konsumen yang dijadikan responden paling banyak adalah responden yang 
berusia antara 25 - 27 tahun sebanyak 21 responden dengan presentase sebesar $51,0 \%$, responden yang berusia antara $22-24$ tahun sebanyak 12 responden dengan presentase sebesar $29,0 \%$. Sedangkan sisanya diikuti oleh responden yang berusia $18-21$ tahun sebanyak 8 responden dengan presentasi sebesar 20,0\%. Data tersebut dapat disumpulkan bahwa didominasi oleh responden yang berusia antara 25 - 27 tahun.

Dengan menggunakan software SPSS versi 23 dalam menghitung korelasi maka didapat korelasi antara skor item dengan skor total item yang merupakan uji validitas instrumen dengan ketentuan dinyatakan valid jika korelasinya lebih besar dari kriterianya.

Tabel 3. Uji Validitas Citra Merek

\begin{tabular}{cccc}
\hline Pernyataan & Korelasi & Kriteria & Keterangan \\
\hline CM1 & 0,775 & 0,3 & Valid \\
\hline CM2 & 0,728 & 0,3 & Valid \\
\hline CM3 & 0,768 & 0,3 & Valid \\
\hline CM4 & 0,725 & 0,3 & Valid \\
\hline CM5 & 0,722 & 0,3 & Valid \\
\hline CM6 & 0,627 & 0,3 & Valid \\
\hline
\end{tabular}

Tabel 3 merupakan pengujian validitas untuk instrumen merek yang menunjukan bahwa ada 6 item pernyataan memiliki nilai korelasi yang lebih besar dari pada kriterianya sehingga dinyatakan valid secara keseluruhan. Rentang nilai koefisiensi adalah $0,627-0,775$.

Tabel 4. Uji Validitas Variabel Kepuasan Konsumen

\begin{tabular}{cccc}
\hline Pernyataan & Korelasi & Kriteria & Keterangan \\
\hline KK1 & 0,728 & 0,3 & Valid \\
\hline KK2 & 0,794 & 0,3 & Valid \\
\hline KK3 & 0,840 & 0,3 & Valid \\
\hline KK4 & 0,750 & 0,3 & Valid \\
\hline KK5 & 0,912 & 0,3 & Valid \\
\hline KK6 & 0,777 & 0,3 & Valid \\
\hline KK7 & 0,888 & 0,3 & Valid \\
\hline KK8 & 0,861 & 0,3 & Valid \\
\hline KK9 & 0,681 & 0,3 & Valid \\
\hline KK10 & 0,794 & 0,3 & Valid
\end{tabular}


Tabel 4 merupakan pengujian validitas untuk instrumen promosi yang menunjukan bahwa ada 10 item, secara keseluruhan item tersebut lebih besar korelasinya dari pada kriterianya dan dinyatakan valid. Rentang nilai koefisiensi untuk tabel 4.4 adalah $0,681-0,912$.

Tabel 5. Uji Validitas Variabel Loyalitas Merek

\begin{tabular}{cccc}
\hline Pernyataan & Korelasi & Kriteria & Keterangan \\
\hline LK1 & 0,532 & 0,3 & Valid \\
\hline LK2 & 0,657 & 0,3 & Valid \\
\hline LK3 & 0,527 & 0,3 & Valid \\
\hline LK4 & 0,648 & 0,3 & Valid \\
\hline LK5 & 0,796 & 0,3 & Valid \\
\hline LK6 & 0,773 & 0,3 & Valid \\
\hline LK7 & 0,752 & 0,3 & Valid \\
\hline LK8 & 0,751 & 0,3 & Valid \\
\hline LK9 & 0,686 & 0,3 & Valid \\
\hline KK10 & 0,730 & 0,3 & Valid
\end{tabular}

Tabel 5 merupakan pengujian validitas untuk instrumen loyalitas merek yang menunjukkan bahwa ada 10 item, secara keseluruhan item pernyataan lebih besar korelasinya dari pada kriterianya dan dinyatakan valid. Rentang nilai koefisiensi untuk tabel 4.5 adalah $0,527-0,796$.

Uji reliabilitas untuk menunjukan sejauh mana pengukuran ini dapat memberikan hasil yang relatif tidak berbeda bila dilakukan pengukuran kembali terhadap subjek yang sama. Variabel dikatakan reliabel jika memberikan nilai koefisien > 0,6 (Siregar, 2014:57).

Berikut pengukuran reliabilitas dari semua pernyataan variabel yang disajikan dalam tabel berikut :

Tabel 6. Uji Reliabilitas Variabel

\begin{tabular}{ccccc}
\hline Variabel & $\begin{array}{c}\text { Cronbach's } \\
\text { Alpha }\end{array}$ & $\begin{array}{c}\text { N of } \\
\text { Items }\end{array}$ & Kriteria & Keterangan \\
\hline Citra Merek & 0,813 & 6 & 0,60 & Reliabel \\
\hline $\begin{array}{c}\text { Kepuasan } \\
\text { Konsumen }\end{array}$ & 0,937 & 10 & 0,60 & Reliabel \\
\hline $\begin{array}{c}\text { Loyalitas } \\
\text { Merek }\end{array}$ & 0,867 & 10 & 0,60 & Reliabel \\
\hline
\end{tabular}


Dari pengujian reliabilitas tersebut dapat dilihat bahwa instrumen citra merek, kepuasan konsumen, dan loyalitas merek dinyatakan reliabel karena pada tabel 6 diatas menunjukan bahwa Cronbach's alpa $\geq 0,6$.

Berdasarkan Uji F (Simultan) dan Uji t (Parsial) hasil dari uji F menunjukkan nilai signifikan $0,00<0,05$, dengan demikian hipotesis yang menyatak citra merek dan kepuasan konsumen secara bersama-sama berpengaruh secara signifikan terhadap loyalitas merek dapat diterima. Besarnya nilai koefisien determinasi adalah 66,80 artinya variasi pada loyalitas merek dapat dijelaskan sebanyak 66,80 oleh variabel citra merek dan kepuasan konsumen. Sisanya sebanyak 33,20\% dijelaskan oleh variabel lain yang tidak diteliti. Selain uji F, hasil uji T pada hipotesis yang menyatakan citra merek berpengaruh secara signifikan terhadap loyalitas merek dapat terbukti. Hal ini dapat dilihat dari nilai signifikan $0,00<0,05$ hal ini berarti $\mathrm{H} 0$ ditolak sehingga dapat disimpulkan terdapat pengaruh yang positif dan signifikan antara citra merek terhadap loyalitas merek. Citra merek yang baik harus selalu dijaga, bahkan harus ditingkatkan guna lebih baik lagi.

Citra merek yang baik diharapkan mampu menghasilkan loyalitas merek yang baik dan pembelian berulang sehingga mampu menghasilkan dampak yang positif bagi perusahaan. Hasil penelitian ini sejalan dengan hasil penelitian yang dilakukan oleh (Bastian, 2014), Moh Rizan (2013) yang menyatakan bahwa citra merek berpengaruh secara positif dan signifikan terhadap loyalitas merek. Disamping itu juga penelitian ini menolak hasil penelitian yang dilakukan oleh (DEWI, 2015) yang menyatakan citra merek tidak berpengaruh terhadap loyalitas merek. Pada variabel kepuasan konsumen nilai signifikan $0,00<0,05$, hal ini berarti $\mathrm{HO}$ ditolak sehingga dapat disimpulkan bahwa terdapat pengaruh yang positif dan signifikan antara kepuasan konsumen terhadap loyalitas merek. Kepuasan konsumen pada dasarnya memiliki peran yang penting dalam loyalitas merek.

Dengan adanya kepuasan konsumen maka akan menjadi tahu seberapa puas dan loyal terhadap produk tersebut. Sehingga produk tersebut tidak asing lagi ditelinga konsumen. Semakin dikenal produk tersebut maka semakin brpeluang besar konsumen memutuskan untuk membeli produk tersebut pula. Hasil penelitian ini sejalan dengan hasil penelitian yang dilakukan oleh (Hanifa et al., 2019) yang menunjukan hasil bahwa kepuasan konsumen mempunyai pengaruh yang signifikan terhadap loyalitas merek. 
Disamping itu juga penelitian ini menolak hasil penelitian yang dilakukan oleh (Purnama, 2018) yang menunjukkan hasil bahwa kepuasan konsumen tidak berpengaruh positif terhadap loyalitas merek.

\section{4.}

\section{SIMPULAN}

Berdasarkan hasil penelitian dan pembahasn mengenai "Pengaruh Citra Merek dan Kepuasan Konsumen Terhadap Loyalitas Merek Mie Instan Indomie pada Alfamart Cabang Putat" maka dapat disimpulkan Citra merek, Kepuasan Konsumen dan Loyalitas Merek Mie Instan Indomie pada Alfamart Cabang Putat termasuk dalam kriteria tinggi, mempunyai pengaruh yang positif dan signifikan terhadap loyalitas merek Mie Instan Indomie, hal ini menunjukan bahwa semakin tinggi citra merek maka akan menyebabkan loyalitas merek meningkat. Kepuasan konsumen mempunyai pengaruh yang positif dan signifikan terhadap loyalitas merek Mie Instan Indomie, hal ini menunjukan bahwa semakin tinggi kepuasan konsumen maka akan menyebabkan loyalitas merek meningkat, konsumen secara bersama-sama berpengaruh secara signifikan dan positif terhadap loyalitas merek Mie Instan Indomie dapat diterima.

\section{DAFTAR PUSTAKA}

Bastian, D. A. (2014). Analisa Pengaruh Citra Merek (Brand Image) dan Kepercayaan Merek (Brand Trust) Terhadap Loyalitas Merek (Brand Loyalty) ADES PT. Ades Alfindo Putra Setia. Jurnal Manajemen Pemasaran Petra, 2(1), 1-9.

DEWI, L. N. (2015). Business essentials (10th Ed). Jurnal Riset Ekonomi, Manajemen, Bisnis Dan Akuntansi, 1-17. Retrieved from http://eprints.dinus.ac.id/17594/

Hanifa, O., Kurniawati, T., \& Rahmidani, R. (2019). Pengaruh Harga Dan Kualitas Layanan Terhadap Loyalitas Pelanggan Go-Jek Dengan Kepuasan Pelanggan Sebagai Variabel Mediasipada Mahasiswa Universitas Negeri Padang. Jurnal Ecogen, 1(4), 794. doi: 10.24036/jmpe.v1i4.5658

Nandya Ayu Putri, Zainul Arifin, W. (2016). Pengaruh Citra Merek, Kepercayaan Merek, dan Switching Barrier Terhadap Kepuasan Pelanggan dan Dampaknya Pada Loyalitas Pelanggan. Administrasi Bisnis, 32 No. 1 M, 18-26.

Purnama, P. M. (2018). Konsumen Wedding Organizer. Jurnal Ilmu Manajemen, 7, 140-152. 
Suliyanto. (2017). Pelatihan Metode Pelatihan Kuantitatif. Journal of Chemical Information and Modeling, 5(2), 223-232. 